\title{
Study on the Professional Nursing System of Regional Rehabilitation and Rehabilitation in International Tourist Island
}

\author{
Chenyun Xu${ }^{1}$, Chunru Wang2 ${ }^{*}$, Duoyu Wu ${ }^{1}$, Min Guo ${ }^{1 *}$ \\ ${ }^{1}$ Hainan Provincial People's Hospital, Haikou, China \\ ${ }^{2}$ Qionghai People's Hospital, Haikou, China \\ Email: ^g2002m@163.com
}

How to cite this paper: Xu, C. Y., Wang, C. R., Wu, D. Y., \& Guo, M. (2020). Study on the Professional Nursing System of Regional Rehabilitation and Rehabilitation in International Tourist Island. Journal of Service Science and Management, 13, 336-344. https://doi.org/10.4236/jssm.2020.132022

Received: March 11, 2020

Accepted: April 19, 2020

Published: April 22, 2020

Copyright $\odot 2020$ by author(s) and Scientific Research Publishing Inc. This work is licensed under the Creative Commons Attribution International License (CC BY 4.0).

http://creativecommons.org/licenses/by/4.0/

\begin{abstract}
Hainan will take the construction of an international tourist island as an opportunity to encourage, guide and support the development of the rehabilitation and health tourism industry. Medical tourism is a tourism service with the theme of medical care, rehabilitation and recreation as a concept of sustainable development. The regional rehabilitation nursing network in Hainan cultivates a group of health tourism rehabilitation professional nursing teams that meet the requirements of domestic and foreign countries, strengthens the rehabilitation professional nursing work, builds characteristic tourism rehabilitation professional nursing brands, actively creates regional medical rehabilitation health tourism demonstration bases, and optimizes international Medical tourism rehabilitation nursing service project, creating a regional medical rehabilitation health tourism rehabilitation nursing demonstration base, strengthening the construction of national nursing specialty, and finally establishing a Hainan International Tourism Island regional rehabilitation nursing professional nursing system in Hainan Province. Providing domestic medical tourism rehabilitation nursing services, reference models can be used to provide high-quality medical tourism rehabilitation nursing services for international tourist islands.
\end{abstract}

\section{Keywords}

International Tourism Island, International Tourism Island, Rehabilitation, Rehabilitation, Professional Nursing/Professional Nursing

\section{Introduction}

Rehabilitation nursing is a discipline based on the theory of rehabilitation medi- 
cine and nursing science, researching nursing theories, knowledge, and skills that promote the physiology and psychological rehabilitation of the injured, sick, and disabled. The development of rehabilitation nursing has only a history of more than ten years. There is no unified understanding of its subject research scope (Medical Education Network, 2008). At present, most tertiary and secondary hospitals in China have rehabilitation departments and/or rehabilitation wards (Jiang, 2010), but regional rehabilitation care has not yet formed. Industry lacks of a number of subacute rehabilitation-oriented medical institutions (Qin et al., 2013). In 2010, the State issued the "Several Opinions of the State Council on Promoting the Construction and Development of Hainan International Tourism Island". Hainan will take the opportunity of international tourism island construction as an opportunity to encourage, guide and support the development of the rehabilitation and health tourism industry. In Hainan, there is no real medical tourism project that has been developed in cooperation with medical institutions. Hainan's hospitals did not choose medical models and are only willing to undertake the tasks undertaken by medical institutions. Based on this, we will take the construction of Hainan International Tourism Island as an opportunity. The construction of an international tourism island is an opportunity to establish a Hainan regional rehabilitation and nursing professional nursing system, build an international tourism island medical tourism construction rehabilitation care service brand, and provide high-quality medical tourism rehabilitation nursing services to the international tourism island.

\section{Status of Rehabilitation Nursing Systems at Home and Abroad}

World Tourism Organization (World Tourism Organization) in order to continuously popularize the concept of tourism to the world, form a good tourism development environment, and promote the continuous development of the world tourism industry, it is a form of tourism that combines tourism and health services. Medical tourism refers to tourist. You can choose the appropriate tourist area according to your condition and the doctor's advice, and enjoy while traveling Butler Services, effective health management, and physical and mental health. Refers to an emerging industry that seeks suitable medical services abroad and combines leisure tourism because of the expensive or incomplete medical services in the settlements. Popularize the tourism concept to the world, form a good tourism development environment, and promote the continuous development of the world's tourism industry.

Domestic status quo: China has not yet established a regional system that combines medical tourism and rehabilitation and nursing. The Shanghai medical tourism product development and promotion platform was officially put into operation in 2010, filling China's gap in international medical tourism (Xu et al., 2013), but did not combine medical tourism with rehabilitation professional nursing, nor did it establish a regional rehabilitation nursing care system.

Status of foreign countries: Status of foreign countries: Medical tourism ori- 
ginated in Europe, Switzerland, Germany, Hungary, Lithuania, etc. are all international medical tourism reception centers. Medical tourism in other countries has developed rapidly, such as the three "magic" of Indian medical tourism (environment, cheap, Services), South Korea's cosmetic surgery, stem cell therapy, Malaysia's low-cost medical examination services, Singapore's sophisticated medical services, etc. The destination of tourism has shifted from developed countries with higher levels of medical services to developing countries with cheaper medical services, and Created huge economic benefits. Driven by the globalization trend, medical tourism packaged with exotic tourism is booming, and international medical tourism has become one of the largest industries in the world. In the face of huge market demand, travel agencies and Domestic medical institutions should jointly launch medical tourism packages suitable for China's national conditions, and under the management of relevant industry policies, organically integrate existing resources, promote and drive the development of related service industries, form a new service industry model, and promote further economic development. In addition, medical institutions also need to focus on improving their supporting services. In terms of insurance, reimbursement and living services, all must conform to the habits of international patients, so that they can occupy a favorable market position in the upcoming medical tourism boom.

\section{The Value of Establishing a Regional Rehabilitation Professional Nursing System in Hainan International Tourism Island}

1) Establish a management mode for regional rehabilitation nursing in Hainan International Tourism Island

At present, China's overall rehabilitation care is still in the enlightenment stage, and the development of each stage is relatively lagging behind, and there is a big gap between the growing demand for rehabilitation care in the country and in Hainan Province. The overall thinking of the development of nursing services, the improvement of supporting policies and measures, the improvement of related theoretical systems, and the reference to foreign advanced theories and methods, incorporate rehabilitation nursing service institutions, admissions, and practices into the overall medical and health service system for construction and planning.

a) Determine the content of regional rehabilitation care

In today's society, people's needs for health and quality of life are constantly increasing. At the same time, the changes in the spectrum of human diseases and the change in medical models are becoming more and more recognized around the world. Extending to various clinical disciplines and becoming an irreplaceable important part of modern medicine. For example: Japanese professor Yumoto Sumoto, Bobath rehabilitation technology is used in the rehabilitation of acute and convalescent cerebrovascular disease in Japan (Yang et al., 2014). The scope of services is extended to mental health, Nutrition, sports medicine, plastic 
surgery and other aspects. It is a new field of rehabilitation medicine and nursing in the 21st century.

The construction of rehabilitation medicine and nursing is a systematic project, which involves multiple departments of the health system. The recognized leaders attach great importance to the measures in place. A modern rehabilitation medicine and nursing adapted to the development of the problem will surely be built and healthy. Development will surely be built and got healthy development. It has been 14 years since I initially joined WHO, and the reform is gradually deepening under the leadership of the new government. The country is building more and more social security systems, paying attention to vulnerable groups, and paying attention to people with disabilities. The return of disabled people to society has become a requirement of the times, and it is also a sign of the civilization of a country.

b) Establish a regional rehabilitation nursing management network system

Implement network management of regional rehabilitation nursing management, organically integrate standardized rehabilitation nursing content and rehabilitation specialist nurse training, assessment, and evaluation into the network, so that the regional rehabilitation nursing service content in Hainan Province is more complete and the service content is richer. Provide better medical and health services on higher platforms and levels, provide teams on the network with full coverage, comprehensive, full-process, zero-distance health services, health supervision, emergency treatment services, and the quality and efficiency of rehabilitation care.

c) Select some regions for pilot work

Standardize the connotation of rehabilitation nursing, further improve the pilot scheme of rehabilitation and nursing services, select some regions to carry out pilot work, and successfully push it to the entire region of Hainan. The research organization of this experience is Hainan Provincial People's Hospital.

\section{Establish a Coordinated and Coordinated Rehabilitation Care System Adapted to the Hainan International Tourism Island}

According to the "Guidelines on Rehabilitation Medical Work during the" Twelfth Five-Year Plan "period issued by the Ministry of Health, we should establish a layered and phased rehabilitation medical service system to gradually realize the patient's participation in general hospitals, rehabilitation hospitals, and basic medical and health institutions to realize the graded medical treatment and two-way referral of patients. Based on the Ministry of Health's policies and the current status of international tourist islands, we will establish a coordinated and coordinated rehabilitation care system.

1) Adopt a more mature model at home and abroad: "One Belt, Three Models": The first level is the "leading", which is a guiding and leading role, which is carried by the experts of the nursing department of the general hospital at the 
third level and above, and guides and leads 3 or more municipal and county-level medical units; the second level is "key", which is to play the role of implementation and policy implementation. It is carried by rehabilitation care experts at 3 or more municipal or county-level hospitals or general hospitals, each of which guides and leads 3 third-level units; the third level is "foundation", which is the role of implementing feedback: it is carried by 9 hospitals or township hospitals in the tourism area. In this way, 1 leading band with 3 key points, and 3 key bands with 9 base points, finally, a rehabilitation care system (Liu, 2013) that is point-to-face and guides feedback is formed.

2) Establish and improve the health records of rehabilitation care objects. Unify the requirements for writing health records, establish the provincial health archives, implement information management, share resources across the province, and update and improve in real time. Implement the "annual review system" for rehabilitation nursing institutions at all levels. "Eliminate unqualified rehabilitation nursing service institutions. Establish three norms, namely, institution construction norms, practice behavior norms and personnel training norms.

\section{Establish a Standardized Training, Certification and Management System for Rehabilitation Nursing Practitioners}

Professional nurse qualification certification is a standard industry entry. Its certification requires a high level of professional knowledge, work experience, practical ability, and occupational risk commitment, which far exceeds the basic requirements for practicing registration. At present, even in the province and the country, it has not yet been established. The standardized training and qualification management system for rehabilitation nursing experts, taking advantage of the opportunity of the "leading" hospital to pass the jci international certification in the next few years, establish standardized training and qualification management system for rehabilitation nursing in Hainan Province. Excellent nursing staff from various hospitals at different levels are trained, qualified, and required for a series of international tourism island regional rehabilitation treatments.

In this system, firstly, apply nursing evidence-based methods to formulate training plans and goals, introduce relevant domestic and foreign related nursing talents to train nurses at all levels of hospitals by holding training courses (Xu et al., 2013), and at the same time carry out qualification certification. Secondly, improve the standard system of rehabilitation medical nursing diagnosis and treatment, improve professional ethics, strengthen the quality awareness of rehabilitation nursing services, and standardize the practice. The system construction requires rehabilitation professionals to have professional nurse qualification certification before they can engage in rehabilitation nursing services. 


\section{Establish a Regional Rehabilitation Nursing Quality Evaluation System for Hainan International Tourism Island}

Rehabilitation nursing quality evaluation system, as a service index strictly required by the industry, is a research management method that comprehensively predicts the actual situation of work by evaluating the implementation and results of rehabilitation nursing activities through relevant standards. Therefore, the scientific, standardized and informative Rehabilitation nursing quality assessment system can well ensure the smooth development, implementation and feedback of rehabilitation nursing service projects of medical units at all levels in Hainan Province. This project intends to establish a set of conditions suitable for the development of regional health services in Hainan International Tourism Island. A certain scientific and feasible evaluation index system for the quality of rehabilitation nursing. In this system, the tracking method is the basic method, and the structural quality, process quality, and result quality are the elements, highlighting the rehabilitation prevention, treatment, security, The status quo of the six-in-one function of health, planning, and teaching has good suitability, orientation, and practical application value. Nursing managers should update their concepts, grasp the latest developments, and establish management standards that serve the practice of rehabilitation nursing in order to Promote the quality of emergency care to a high level.

\section{Establish a Psychological Intervention Guidance Center for Rehabilitation Nursing}

Nursing psychology (nursing psychology) refers to the study of individuals under the specific social living conditions of nursing situations from the perspective of interaction between nursing situations and individuals. Mental activity The discipline of occurrence, development and change (Medical Tourism, 2000). The "individual" referred to in this definition is the study of nursing psychology Object Including nurses and patients. That is to say, nursing psychology must study "patients" in the context of nursing. Individual psychology the laws of activities must also study the laws of individual nurses' psychological activities. At present, nursing science written in China has not left the influence of pure biomedical models and other modes. The emphasis is on the operation of biomedical physiological nursing skills in biomedicine, and the application of biomedicine and nursing is carried out. Such nursing science obviously lags behind the development of contemporary medicine. The nursing profession in China urgently needs nursing psychology. Only with the development and popularization of nursing psychology, medical staff can understand the laws of patients' psychological activities and can take the corresponding technology is used for psychological care. In accordance with comprehensive and appropriate care can make patients feel physically comfortable and psychologically Comfortable Therefore, the quality of care is greatly improved. Therefore, in the regional rehabilitation and nursing 
professional nursing system in Hainan Province, the progress and development of rehabilitation and nursing professional nursing will surely gradually integrate biomedical physiological and psychological nursing into one, so that rehabilitation Nursing nursing becomes a systematic science.

\section{The Advantages of Establishing a Regional Rehabilitation Professional Nursing System in Hainan International Tourism Island}

Medical tourism is one of the fastest-growing emerging industries in today's society, especially Asia; Asia has experienced rapid growth in recent years. Last year, medical tourism revenue exceeded US $\$ 190$ billion. The so-called medical tourism is medical treatment under the guidance of the local government. , Rehabilitation care, health care, fitness industry. Drawing on advanced foreign experience, Hainan has developed the advantages of international medical tourism rehabilitation professional nursing services in the following areas:

\subsection{Analysis of the Advantages of Medical Tourism, Rehabilitation and Nursing Professional Nursing Service Industry in Hainan Province}

1) Cheap and high-quality medical services. Labor costs in Hainan are relatively low, medical services are affordable, and medical hardware is gradually being improved.

2) Traditional Chinese medicine and traditional Chinese medicine (Southern medicine) characteristic items. Traditional Chinese medicine also has therapeutic effects in the areas of disease prevention, health rehabilitation and acupuncture, cardiovascular and cerebrovascular diseases, which have laid a good foundation for medical tourism in Hainan Province (Kang, 2013).

3) Rich natural tourism resources. Hainan Province has many excellent natural tourism resources such as hot springs and medicated food.

4) Hainan is rich in ethnic medical services. Hospitals or entrepreneurs can combine various ethnic medical therapies in our province with their unique folk customs to develop ethnic experience medical tourism projects.

5) The medical tourism infrastructure is perfect. Hainan has excellent conditions for the development of medical tourism in terms of time, geography, and harmony. The transportation arteries of the North-South Expressway are very developed. Haikou Meilan International Airport and Sanya Phoenix International Airport have convenient transportation. It makes Sanya, Boao, and Haikou's tourism taste more attractive, and the tourism environment, humanities, and medical treatment of Hainan International Tourism Island are more famous around the world.

\subsection{Basic Trends of Population Aging in Hainan in the Next 10 Years}

The degree of aging will exceed the national average, and it is initially predicted 
that the proportion of the elderly population over the age of 60 in Hainan will reach $18.89 \%$ in 2020 , which is higher than the expected national aging level (about 17\%). In 2020, the proportion of Hainanese people over 80 years of age in Hainan will be $17.09 \%$, which is higher than the national level of $11.3 \%$. The degree of rural aging will further increase. By 2020, the degree of rural aging will reach $26.11 \%$, exceeding the province. The average level (18.89\%) is 7 percentage points. "Migrant bird elderly" will grow rapidly. Preliminary estimates indicate that by 2020, the peak of "migrant bird elderly" will reach around 630,000 (Weng \& Wang 2013).

\section{Conclusion}

Therefore, the idea is to establish the Hainan International Tourism Island Regional Rehabilitation Professional Nursing System for the first time at home and abroad, develop the Hainan Regional Rehabilitation Nursing Network, cultivate a group of health tourism rehabilitation professional nursing teams that meet domestic and foreign requirements, and strengthen the construction of national nursing specialty, establish an evaluation index system for the quality of rehabilitation professional nursing, optimize international medical tourism rehabilitation nursing service projects, create distinctive tourism rehabilitation professional nursing brands, actively create regional medical rehabilitation health tourism demonstration bases, and provide high-quality medical tourism rehabilitation nursing services for international tourism islands. The research on the Hainan International Tourism Island Regional Rehabilitation Professional Nursing System is of great significance and value, and provides an important scientific basis for China's tourism rehabilitation professional nursing work and management model.

\section{Foundation Project}

Hainan Health Commission Science and Technology Project (No. 20A200210).

\section{Conflicts of Interest}

The authors declare no conflicts of interest regarding the publication of this paper.

\section{References}

Jiang, C. Y. (2010). Enlightenment of the Evolution of American Rehabilitation Medical System to China. Chinese Journal of Rehabilitation Medicine, 25, 1188-1190.

Kang, L. R. (2013). Exploration and Practice of Training Mode for Rehabilitation Specialist Nurses. Chinese and Foreign Health Digest, 10, 317-318.

Liu, W. J. (2013). Analysis of the Effect of Nursing Intervention on 42 Elderly Patients with Parkinson Depression. Hainan Medical Journal, 24, 612-613.

Medical Education Network (2008). Overview of the Development of Rehabilitation Nursing.

Medical Tourism. http://baike.sogou.com/v8577478.htm 
Qin, J. X., \& Fang, M. J. (2013). Application of Rapid Surgical Nursing in Laparoscopic Rectal Cancer Surgery. Hainan Medical Journal, 24, 2011-2012.

Weng, S. W., \& Wang, Y. C. (2013). Nursing Progress of Rapid Rehabilitation Surgery in Gastrointestinal Surgery. Hainan Medical Journal, 24, 2703-2705.

Xu, A. H., Xing, L. Y., \& Sun, R. F. (2013). Effect of Nursing Intervention on Rehabilitation Compliance of Elderly Patients with Chronic Obstructive Pulmonary Disease. Hainan Medical Journal, 24, 2791-2792.

Yang, D. R., Li, N., et al. (2014). Rehabilitation Nursing before and after Surgery for Tibial Shaft Fracture with Posterior Cruciate Ligament Injury. Hebei Medical Journal, 20, 1731-1733. 